\title{
LOGÍSTICA REVERSA DE PÓS-CONSUMO DE MEDICAMENTOS EM GOIÂNIA E REGIÃO METROPOLITANA - UM ESTUDO DE CASO
}

\author{
REVERSE LOGISTICS OF POST-CONSUMER MEDICATION WASTE \\ IN GOÂNIA AND ITS METROPOLITAN REGION - A CASE STUDY
}

\author{
LA LOGÍSTICA INVERSA DEL POST-CONSUMO DE MEDICAMENTOS \\ EN GOIÂNIA Y REGIÓN METROPOLITANA - UN ESTUDIO DE CASO
}

\author{
Alessandra Faria da Silva - Universidade Estadual de Goiás - Aparecida de Goiânia - Goiás - Brasil \\ alessandra-208@hotmail.com
}

\author{
Vera Lúcia Francisco Dias Martins - Universidade Estadual de Goiás - Goiânia - Goiás, Brasil \\ vlfdm@uol.com.br
}

\begin{abstract}
Resumo
Este artigo traz um estudo referente à logística reversa de pós-consumo de medicamentos em Goiânia e região metropolitana com o objetivo de analisar o descarte de medicamentos e o impacto socioambiental gerado, vislumbrando a necessidade da criação de uma rede de logística reversa de pós-consumo de medicamentos nos estabelecimentos de comercialização. Apresenta os resultados obtidos por pesquisa qualitativa realizada em estabelecimentos farmacêuticos e drogarias da região, bem como destaca os resultados da pesquisa quantitativa, aplicada na amostra de $2 \%$ desta população, com 0 objetivo de identificar o comportamento dos consumidores com relação ao descarte de medicamentos. A partir dos dados levantados, observa-se a necessidade de soluções para 0 descarte e 0 tratamento correto dos resíduos medicamentosos em benefício do meio ambiente.
\end{abstract}

Palavras-chave: Descarte de medicamentos, impactos socioambientais, logística reversa.

\section{Abstract}

this paper presents a case study on the reverse logistics of post-consumer medication waste in the Brazilian municipality of Goiânia and its metropolitan area whose goal was to assess the process of drug disposal and the resulting social and environmental impacts in order to highlight the need for a reverse logistics network of post-consumer medication waste in commercial establishments. This work presents the results obtained by qualitative analysis in pharmacies and drugstores in the region as well as highlights the results from quantitative analysis carried out on $2 \%$ of this population in order to assess consumers' opinion about medication disposal methods. These results make clear the need for safe disposal and treatment of drug residues for the benefit of the environment.

Keywords: Medication disposal, social and environmental impacts, reverse logistics

\section{Resumen}

Este artículo trae un estudio sobre la logística inversa de post-consumo de medicamentos en Goiânia y en la región metropolitana con el objetivo de examinar el descarte de medicamentos y el impacto socioambiental generado, vislumbrando la necesidad de crear una red de logística inversa de post-consumo de medicamentos en los establecimientos de comercialización. Se presentan los resultados obtenidos en la investigación cualitativa realizada en los establecimientos farmacéuticos y farmacias de la región y se destacan los 
resultados de la investigación cuantitativa aplicada a la muestra del $2 \%$ de esa población, con el objetivo de identificar el comportamiento de los consumidores sobre la eliminación de los medicamentos. A partir de los datos recogidos, se observa la necesidad de soluciones para la eliminación y tratamiento correcto de los desechos medicamentosos en beneficio del medio ambiente.

Palabras clave: Eliminación de medicamentos, impactos socioambientales, logística inversa.

Introdução

É notória a preocupação mundial com relação ao meio ambiente, que direta ou indiretamente aparece como tema de discussões no dia a dia, resultando em reuniões entre lideranças mundiais sobre desenvolvimento sustentável, como por exemplo, a COP 21 (Conferência da ONU para o clima), ocorrida em Paris entre os dias 28 de novembro e 11 de dezembro de 2015. Durante o evento, lideranças de mais de 190 países, incluindo o Brasil, se reuniram para discutir um acordo global que indique às nações metas, planos, ações, instrumentos, entre outras ideias, fomentando que o crescimento e o desenvolvimento da economia ocorram em consonância com o desenvolvimento social e a sustentabilidade do meio ambiente, evitando ou minimizando os impactos ambientais (Leite, 2015).

No contexto da sustentabilidade do meio ambiente, surge a preocupação com resíduos gerados após o consumo de produtos, dentre estes os resíduos medicamentosos. Para o Instituto IMS Health (2015) - organização que audita o mercado farmacêutico mundial -, o Brasil é o país com maior número de farmácias e drogarias do mundo, na proporção de 3,34 farmácias para cada 10 mil habitantes, considerando uma população de 190 milhões de habitantes. De acordo com os dados da Associação Brasileira do Comércio Farmacêutico (ABCFARMA, 2014), existem no Brasil 97.031 farmácias.

A Federação Brasileira das Redes Associativas (FEBRAPAR) revela que as farmácias e drogarias são os principais meios de distribuição de remédios para a população, e que o Brasil se destaca por ser o $4^{\circ}$ mercado de consumo de medicamentos no mundo (SINPRAFARMA ${ }^{1}, 2014$ ).

Levando em consideração o crescimento do mercado farmacêutico no Brasil, o aumento do consumo de medicamentos por parte da população e os problemas ambientais causados pelo descarte inadequado de resíduos de fármacos, este artigo teve por objetivo estudar o descarte de medicamentos de pós-consumo em Goiânia e região metropolitana, bem como conhecer o posicionamento e a dinâmica das farmácias ou drogarias 
que trabalham com a logística reversa de pós-consumo de medicamentos; entender a posição das farmácias ou drogarias que não trabalham com a logística reversa; investigar o comportamento das pessoas com relação ao uso e ao descarte dos medicamentos que consomem; e estudar os impactos ambientais da não realização da coleta de resíduos de medicamentos.

Logo, o problema levantado corresponde em pesquisar a existência de farmácias que praticam a logística reversa de pós-consumo de medicamentos em Goiânia e Região Metropolitana. Considerando como hipóteses a existência de poucas farmácias por visualizarem a prática como um custo e não como oportunidade de investimento; o desconhecimento do conceito de logística reversa de pós-consumo e seus benefícios; a não posse de recursos suficientes para trabalharem com a logística reversa de pós-consumo de medicamentos; ou ainda a não realização da logística reversa de pós-consumo de medicamentos por ineficiência de legislação que obrigue o processo da logística reversa de medicamentos.

Neste sentido, este artigo é divido em cinco partes. Primeiro, uma introdução da temática e seus conceitos. Em seguida, trata do consumo e descarte de medicamentos. Na terceira, são apresentados os conceitos de logística e logística reversa de medicamentos. Na quarta, destaca os materiais e métodos utilizados para a pesquisa, bem como apresenta os resultados obtidos. Por fim, nas considerações finais, recomenda a criação de um sistema de gerenciamento adequado ao descarte de medicamentos em conjunto com programas de sensibilização e educação que informem às pessoas sobre o correto descarte de medicamentos oriundos de sobras ou medicamentos vencidos.

\section{Consumo e descarte de medicamentos}

Conforme Graciani e Ferreira (2014), o consumo de medicamentos ocupa posição de destaque no cenário mundial. As vendas globais da indústria farmacêutica alcançaram um montante de US $\$ 808,3$ bilhões em 2009. Dos quais, US\$ 45,8 bilhões proviam dos sete mercados farmacêuticos mais importantes da América Latina: Argentina, Brasil, Chile, Colômbia, México, Peru e Venezuela. Estudos revelam que as vendas de produtos farmacêuticos estimados nos principais mercados emergentes devem avançar um montante de US\$ 300 bilhões até 2017, 
valor correspondente ao total de vendas conjuntas dos principais mercados da Europa e América do Norte (Spina; Aquino, 2015).

Vaz (2015) informa que só na comercialização de medicamentos genéricos em 2014 foram vendidos 871,7 milhões de unidades de medicamentos no país, gerando um faturamento de $\mathrm{R} \$ 13,7$ bilhões para as empresas do setor.

Segundo Spina e Aquino (2015, p. 3):

O fácil acesso aos medicamentos é um fenômeno que acontece mundialmente, a automedicação, o abuso, o alto número de prescrições são situações que colocam a disposição dos usuários uma variedade de possibilidades.

É consenso entre os autores Ortiz, Boer e Rocha (2014), Spina e Aquino (2015), Alvarenga e Nicoletti (2010), João (2011) e Brandão (2013) de que inúmeras são as causas de sobra de medicamentos, como a prescrição e a compra de medicamentos em quantidade além da necessária para o tratamento, mudança de tratamento, automedicação e disseminação de amostras grátis por parte dos laboratórios farmacêuticos. A presença dos medicamentos em todas as esferas da saúde de maneira desorganizada e sem controle especial após a venda leva a sérios problemas ambientais e de saúde pública (Spina; Aquino, 2015).

Um estudo realizado pela Agência Brasileira de Desenvolvimento Industrial (ABDI) considera que a população brasileira pode gerar mais de 10,3 mil toneladas por ano de resíduos medicamentosos, considerando uma população de 190,7 milhões de habitantes, sem nenhum sistema de descarte adequado. (ABDI, 2013)

Segundo a ABDI (2013), diversos estudos de âmbito internacional apontam que o descarte não judicioso de medicamentos vencidos ou sobras, realizado pela população no lixo comum ou na rede pública de esgoto, implica em riscos para a saúde humana e para o meio ambiente. Dentre os efeitos negativos relacionados à presença de resíduos de medicamentos no meio ambiente, destacam-se os riscos de contaminação do solo, água, flora e fauna.

Os medicamentos não utilizados, principalmente hormônios, amostras, medicamentos para pressão arterial, codeína, e antibióticos, geralmente acabam em aterros sanitários e cursos de água, causando danos irreversíveis aos seres humanos, vida aquática, e para o ambiente em geral (Kongar et al., 2014, p. 51). 
O vice-presidente do Conselho Federal de Farmácia, Walter da Silva Jorge João, afirma que as consequências da presença de fármacos no meio ambiente são pouco conhecidas, porém a preocupação é maior com relação a presença destes na água, pois já se sabe de potenciais efeitos adversos à saúde humana, animal e organismos aquáticos. Além do que, existem medicamentos que exigem atenção redobrada, como os antibióticos e os estrogênios. Os antibióticos, devido à capacidade de influenciar o desenvolvimento de bactérias resistentes, e os estrogênios, por poderem afetar o sistema reprodutivo dos animais aquáticos, como por exemplo, causar a feminização de peixes machos existentes em rios contaminados com o descarte de efluentes (João, 2011).

Spina e Aquino (2015) acrescentam, a partir de estudos realizados no Brasil, que a maioria dos medicamentos é descartada de forma errada, contaminando o solo, lençóis freáticos, meio ambiente e, principalmente, causando intoxicação das pessoas. O Sistema Nacional de Informações Tóxico-Farmacológicas da Fundação Oswaldo Cruz (SINITOX, 2016) esclarece, a partir de estatísticas, que os medicamentos respondem por $27 \%$ das intoxicações no Brasil, e 16\% dos casos de morte por intoxicações são causadas por medicamentos.

Segundo Kongar et al. (2014), a maioria dos medicamentos não se tornam tóxicos após a data de validade, porém alguns, como os medicamentos para tratamento do câncer e HIV, antibióticos, diluentes do sangue, e drogas quimioterápicas, ao serem descartados incorretamente, são altamente nocivos para a saúde humana e para o meio ambiente.

Existem nos Estados Unidos e na Europa inúmeros programas de gerenciamento dos medicamentos descartados pela população. Incluem desde programas de coleta e redistribuição de medicamentos, em plena condição de uso, para pessoas carentes que não possuem recursos suficientes para comprar determinados medicamentos; programas de sensibilização para a disposição adequada dos fármacos; programas de retorno de drogas com prescrição em tratamentos interrompidos pelo paciente; até O Programa de extensão da validade do medicamento, desenvolvido pela FDA (Food and Drug Administration - EUA), baseado em testes químicos laboratoriais, que testam a estabilidade das drogas após a expiração. Tais testes indicaram que uma quantidade de medicamentos expirados na embalagem original fechada pode permanecer estável por um período médio de 57 meses após a data de 
validade, o que possibilita a revenda do medicamento ou mesmo a doação do mesmo (Kongar et al., 2014).

É importante ressaltar que a criação desses programas está associada não só a uma questão social e ambiental, mas principalmente a uma questão política, na qual, leis e regulamentos foram criados pelo legislativo desses países de forma a incentivar e implementar o gerenciamento dos produtos farmacêuticos, dando margem para que diversas organizações e instituições lançassem iniciativas para programas de retorno de drogas de maneira segura, legal e benéfica ao meio ambiente.

\section{A logística reversa dos medicamentos}

Os processos de movimentação da cadeia de suprimento dos medicamentos são realizados pela logística empresarial, também conhecida por administração de materiais, administração de transportes, ou ainda distribuição física, tendo como objetivo levar para o cliente bens e serviços corretos, no lugar certo, no tempo exato e da forma desejada ao menor custo possível, por meio da administração eficiente e eficaz das atividades logísticas (Ballou, 2010).

Já o processo logístico de retorno dos bens usados ou em desuso à cadeia produtiva de origem, para o seu devido e adequado fim, é denominado de Logística Reversa. Segundo Leite (2009, p. 17):

A logística reversa é a área da logística empresarial que planeja, opera e controla o fluxo e as informações logísticas correspondentes, do retorno de bens de pós-venda e de pós-consumo ao ciclo de negócios ou ao ciclo produtivo, por meio dos canais de distribuição reversos, agregando-lhes valores de diversas naturezas: econômico, de proteção, de serviços, ecológico, legal, logístico, de imagem coorporativa, dentre outros.

A variedade e a quantidade de produtos produzidos pelas empresas através de reduzidos ciclos de vida mercadológicos têm como objetivo dar espaço para o lançamento de novos modelos, o que resulta em excesso de produtos consumidos ou não utilizados descartados indevidamente no ambiente, provocando poluição, contaminação, além de gerar riscos à saúde pública. Para Leite (2009, p. 14), “a tendência a descartabilidade acentua-se como uma realidade em nossos dias”. 
Com a globalização, a alta competitividade entre as empresas, e os novos interesses sociais, ambientais e governamentais, exige-se das empresas práticas que resolvam a questão da quantidade de produtos de pós-venda e de pós-consumo que não retornam ao ciclo produtivo ou de negócios. No sentido de agregar valor a esses produtos, ou de dar a melhor destinação e tratamento corretos sem provocar ou mesmo minimizar impactos ambientais. Nesse contexto, Dias (2012), aponta os cinco fatores que contribuíram por destacar a logística reversa, sendo eles: aumento dos problemas ambientais; lotação dos aterros sanitários; a economia de matérias-primas; legislação ambiental e o consumidor mais exigente e criativo.

Os canais de distribuição reversos são definidos por Leite (2009) como canais reversos de pós-venda e de pós-consumo. Os canais de distribuição reversos de pós-venda são formados pelas diferentes maneiras e possibilidades de retorno de bens de pós-venda do consumidor ao fabricante.

Enquanto isso, os produtos de pós-consumo retornam após o fim da sua vida útil, quando o consumidor não vê mais nenhuma serventia no produto e o descarta. Segundo Leite (2009) é nesta fase que entra a logística reversa, que por meio dos canais reversos deve equacionar o retorno desses bens, dando a estes a destinação mais adequada.

O conceito de logística reversa evoluiu para a gestão da cadeia de suprimentos verde, Green Supply Chain Management, que, nas palavras de Silva, Sarquis e Tondolo (2013), corresponde à conscientização ambiental sendo pensada pelo conjunto de empresas conectadas, desde o design do produto, procura e seleção de matérias, processos de produção, entrega do produto final, como também à gestão após a utilização da vida útil do produto vendido.

Dentre as razões que levam as empresas a praticarem a logística reversa, Mueller (2005) e Liva, Oliveira e Pontelo (2002) destacam: relação custo/benefício vantajosa; imagem da empresa perante o mercado; diminuição dos custos e proteção do meio ambiente.

No Brasil não há uma legislação específica, rígida e estimulante sobre o assunto, o pouco que há é tratado na Política Nacional de Resíduos Sólidos (PNRS) (Brasília, 2012) e na Resolução da Diretoria Colegiada, sendo escassos os programas de gerenciamento de retorno de medicamentos. 
Segundo Graciani e Ferreira (2014), mesmo que os resíduos de medicamentos não estejam previstos no artigo 33 da PNRS, que determina a obrigatoriedade da aplicação da logística reversa para os setores de agrotóxicos, pilhas e baterias, pneus, óleos lubrificantes, lâmpadas fluorescentes, e produtos eletroeletrônicos e seus componentes, a lei apresenta mecanismos para extensão deste instrumento. Instruídos nos parágrafos $1^{\circ}$ e $2^{\circ}$ desse mesmo artigo, que estabelecem que havendo a viabilidade técnica e econômica além do nível e amplitude do impacto de certos resíduos à saúde e ao meio ambiente, fica estipulado a aplicação do sistema de logística reversa a outros produtos e embalagens por meio de previsão em regulamento, termos de compromisso ou acordo setorial. Desta forma, a previsão se torna genérica e mantém aberta e possível a aplicabilidade da logística reversa a outros setores que não aqueles especificamente mencionados na legislação.

\section{Material e Métodos}

A presente pesquisa fundamentou-se em etapas sucessivas de atividades de campo e busca ativa de referências bibliográficas. Os resultados obtidos apresentam caráter qualitativo e quantitativo, na medida em que possuem um universo amostral bem definido nos municípios selecionados.

A investigação foi compartimentada em etapas. Em um primeiro momento, teve como foco a questão qualitativa, a qual baseou-se no estudo de caso de 12 farmácias e drogarias, nas quais foram realizadas entrevistas com gerentes e farmacêuticos, de forma presencial, utilizando um roteiro estruturado por dez perguntas, sendo nove perguntas fechadas e uma pergunta aberta. O objetivo das entrevistas foi analisar o conhecimento destes profissionais sobre as práticas de logística reversa de medicamentos e levantar se o estabelecimento realiza a coleta e o tratamento dos resíduos e de que forma isso acontece. As entrevistas foram realizadas durante o mês de agosto de 2015.

Para a definição da amostra pesquisada, levou-se em consideração o quantitativo de Farmácias/Drogarias situadas na cidade de Goiânia e região metropolitana (Aparecida de Goiânia, Senador Canedo e Trindade). 
Tabela 1 - Número de Farmácias e Drogarias existentes em cada cidade investigada

\begin{tabular}{|c|c|c|c|c|c|}
\hline Cidade & Aparecida de Goiânia & Goiânia & Senador Canedo & Trindade & Total \\
\hline Quantidade & 222 & 809 & 45 & 57 & 1133 \\
\hline
\end{tabular}

Fonte: Conselho Regional de Farmácia do Estado de Goiás, 2015 (Elaborada pelas autoras).

Os dados descritos foram fornecidos pelo Conselho Regional de Farmácia do Estado de Goiás (CRF-GO, 2015), mais precisamente pela Gerência de Fiscalização. A amostra utilizada inicialmente teve como norte doze estabelecimentos, sendo oito pertencentes a redes de farmácias e quatro a drogarias independentes.

Em entrevistas realizadas nas oito farmácias das redes foi observado que elas possuem como critério obrigatório de funcionamento a necessidade de seguir procedimentos padrões. Diante disso, levando em consideração que as perguntas elaboradas para as entrevistas estavam alinhadas aos procedimentos obrigatórios, concluiu-se que tais respostas seriam idênticas no caso da realização da entrevista nas outras farmácias pertencentes às redes. Esta análise proporcionou à pesquisa um aumento direto no estudo, ampliando o total de estabelecimentos pesquisados para 147, o que corresponde a 12,97\% do total de 1.133 farmácias/drogarias.

Tabela 2 - Distribuição das Farmácias por Região

\begin{tabular}{|c|c|c|c|c|c|}
\hline \multirow{2}{*}{$\begin{array}{c}\text { Redes } \\
\text { /Drogarias }\end{array}$} & \multicolumn{4}{|c|}{ Quantidade de Estabelecimentos por Região } & \multirow[b]{2}{*}{ Total } \\
\hline & Goiânia & $\begin{array}{l}\text { Aparecida de } \\
\text { Goiânia }\end{array}$ & $\begin{array}{l}\text { Senador } \\
\text { Canedo }\end{array}$ & Trindade & \\
\hline 01 & 9 & 4 & 1 & 2 & 16 \\
\hline 02 & 7 & 3 & - & - & 10 \\
\hline 03 & 8 & 3 & - & 1 & 12 \\
\hline 04 & 21 & 7 & 2 & 3 & 33 \\
\hline 05 & 16 & 8 & 4 & 2 & 30 \\
\hline 06 & 12 & 7 & 2 & 2 & 24 \\
\hline 07 & 2 & - & - & - & 2 \\
\hline 08 & 7 & 5 & 1 & 3 & 16 \\
\hline Drog. 01 & 1 & - & - & - & 1 \\
\hline Drog. 02 & - & 1 & - & - & 1 \\
\hline Drog. 03 & 1 & - & - & - & 1 \\
\hline Drog. 04 & - & 1 & - & - & 1 \\
\hline & & Total & & & 147 \\
\hline
\end{tabular}

Fonte: Elaborada pelas autoras com base na coleta de dados, 2015. 
No segundo momento, a pesquisa quantitativa foi direcionada para o público geral, utilizando como instrumento um questionário composto por dez questões fechadas, sendo três questões de múltipla escolha com intuito de identificar o perfil do pesquisado; duas questões voltadas ao comportamento de aquisição de medicamentos e frequência do acompanhamento do prazo de validade destes produtos; três questões em atenção à forma de descarte dos medicamentos que sobram no pósconsumo; e por fim, duas questões com objetivo de verificar a consciência do pesquisado quanto ao impacto gerado pelo resíduo dos medicamentos.

A pesquisa quantitativa foi realizada através da aplicação de questionário à população de quatro municípios que fazem parte da região metropolitana de Goiânia, localizada no Estado de Goiás, no centrooeste brasileiro. As pesquisas aconteceram no período de setembro a novembro de 2015, tendo como público entrevistado estudantes do ensino médio, universitários, funcionários públicos, empresários, comerciários, industriários, trabalhadores autônomos e donas de casa, com faixa etária a partir dos 18 anos de idade.

A definição da amostra foi baseada no quantitativo da população de Goiânia, Aparecida de Goiânia, Trindade e Senador Canedo. Segundo dados do IBGE (2010), o somatório da população destes municípios é de aproximadamente 1.946.589 habitantes. A amostra utilizada refere-se a $2 \%$ deste universo.

Desta forma, foram aplicados questionários a uma amostra de 390 pessoas, sendo 140 em Goiânia, 180 em Aparecida de Goiânia, 30 em Senador Canedo e 40 em Trindade. Ao serem abordados, os participantes eram convidados a preencher o questionário e devolver sem identificação. A pesquisa foi aplicada em diversos locais, como: escolas, universidades, comércio, residências, farmácias, terminais de ônibus, dentre outros.

\section{Resultados e Discussões}

De acordo com as pesquisas realizadas através de entrevista com gerentes e farmacêuticos nas Farmácias e Drogarias, e pesquisa com os usuários de modo geral, obteve-se os seguintes resultados:

\section{Parte 01 - Entrevista nas Farmácias}

Com os dados representados no Gráfico 1 sobre o perfil do entrevistado, constatou-se que $67 \%$ dos entrevistados são gerentes e outros 
33\% farmacêuticos. Quanto ao conhecimento sobre Logística Reversa, perguntou-se se os entrevistados conheciam ou já ouviram falar sobre o termo. Observamos que 50\% deles responderam que "sim" ao passo que os outros 50\% responderam que "não". Pelo cargo de gestão que ocupam era esperado que o percentual de sim fosse superior do que o obtido, o que gera uma preocupação quanto à discussão da importância do assunto no setor de medicamentos.

Quanto à aplicação da Logística Reversa, 67\% disseram que não realizam a logística reversa de pós-consumo de medicamentos, versus $33 \%$ que afirmaram realizá-la. Os 67\% entrevistados que responderam não realizar a logística reversa de pós-consumo de medicamentos se justificaram alegando que: a) Conhecem o que é logística reversa, mas não veem viabilidade em utilizá-la (38\%); b) Não realizam por desconhecer o que é logística reversa (25\%); c) Não praticam por não possuir recursos suficientes para implantá-la (12\%); d) Os demais entrevistados, que correspondem a $25 \%$, relataram outros motivos. É importante destacar que dentre estes outros motivos houve a alegação de que a empresa ainda era nova no mercado, que era um plano para longo prazo e que o público da região onde a empresa está instalada não tinha o perfil.
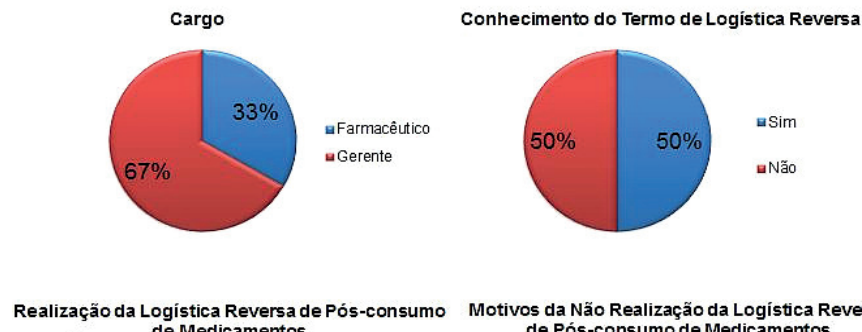

Motivos da Não Realização da Logística Reversa

de Medicamentos de Pós-consumo de Medicamentos
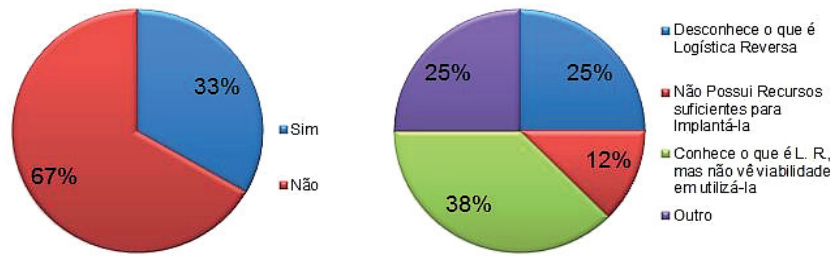

Gráfico 1 - Distribuição dos resultados obtidos com a pesquisa em farmácias e drogarias sobre logística reversa de pós-consumo de medicamentos 
A pesquisa também apontou que das doze farmácias/drogarias pesquisadas, quatro (33\%) realizam algum tipo de logística reversa de pósconsumo de medicamentos, porém cada uma com sua peculiaridade. Vale destacar que uma delas, pertencente a uma rede de farmácias e drogarias, realiza o processo da logística reversa dos medicamentos de pós-consumo de forma diferenciada, pois trabalha em parceria com a empresa BHS Brasil Health Service -, que administra a responsabilidade compartilhada entre as empresas da cadeia produtiva, órgãos públicos, patrocinadores e consumidores, desenvolvendo o programa chamado "Programa Descarte Consciente”, que consiste na adesão por parte das farmácias/drogarias de uma Estação Coletora fornecida pela empresa. A Figura 2 mostra um exemplo de Estação Coletora.

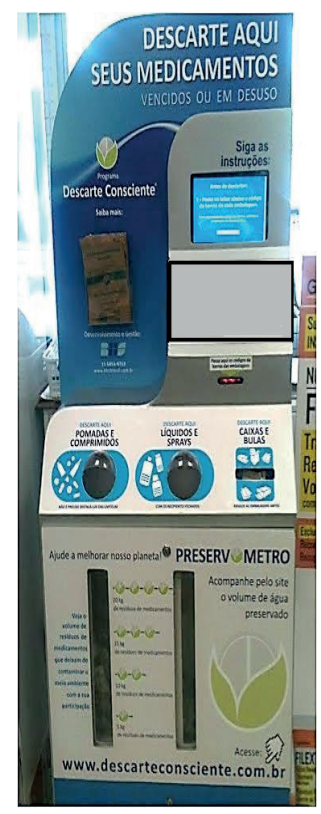

Figura 2 - Estação Coletora

Fonte: $<$ http://www.descarteconsciente.com.br/>.

Conforme Ortiz, Boer e Rocha (2014), também no intuito de favorecer o descarte correto de medicamentos, foi editada pela ANVISA a RDC No 44/2009 (Resolução da Diretoria Colegiada), que no artigo 93 dispõe: 
Art. 93. Fica permitido às farmácias e drogarias participar de programa de coleta de medicamentos a serem descartados pela comunidade, com vistas a preservar a saúde pública e a qualidade do meio ambiente, considerando os princípios da biossegurança de empregar medidas técnicas, administrativas e normativas para prevenir acidentes, preservando a saúde pública e o meio ambiente. (Brasil, 2009).

Desse modo, a logística reversa de medicamentos vem conquistando espaço no cenário brasileiro, no qual muitas empresas e organizações fazem parte desse contexto e muitos mecanismos surgem ampliando a participação de novas organizações na realidade brasileira quanto à afirmação e consolidação da logística reversa de medicamentos no Brasil. Dentre elas, as farmácias e drogarias que constituem elementos centrais do sistema logístico reverso, sejam realizando programas de coleta de medicamentos, atuando como ponto de retorno desses produtos à cadeia produtiva ou como dizem Graciani e Ferreira (2014): “[...] que as farmácias se estabeleçam como centro de saúde dirigido a proporcionar conscientização aos consumidores, não somente quanto ao uso racional, mas também quanto à importância de destinação ambientalmente correta dos resíduos de medicamento".

\section{Parte 02 - Pesquisa de Campo com a População}

Conforme os dados representados nos gráficos 3 e 4, 56\% dos participantes possuíam o ensino superior; 61\% deles tinham entre 18 a 25 anos de idade. Quanto à forma de descarte de medicamentos mais utilizada pelas pessoas, $86,4 \%$ da amostra corresponde ao descarte em lixo comum; em segundo lugar vem o descarte no vaso sanitário, com $5,4 \%$; e somente $1,8 \%$ das pessoas afirmaram realizar o descarte em algum ponto de coleta. Estes dados refletem uma cultura arraigada na população, geralmente estabelecida por falta de informação, que leva a práticas repetitivas de geração para geração. É importante observar que esta falta de informação não condiz necessariamente com o nível de escolaridade dos participantes, já que a maioria apresenta grau de instrução de nível superior, conforme apresentado no Gráfico 3. Para mudar este comportamento se faz necessário a realização de um trabalho de informação e conscientização da população quanto à importância do descarte correto. 


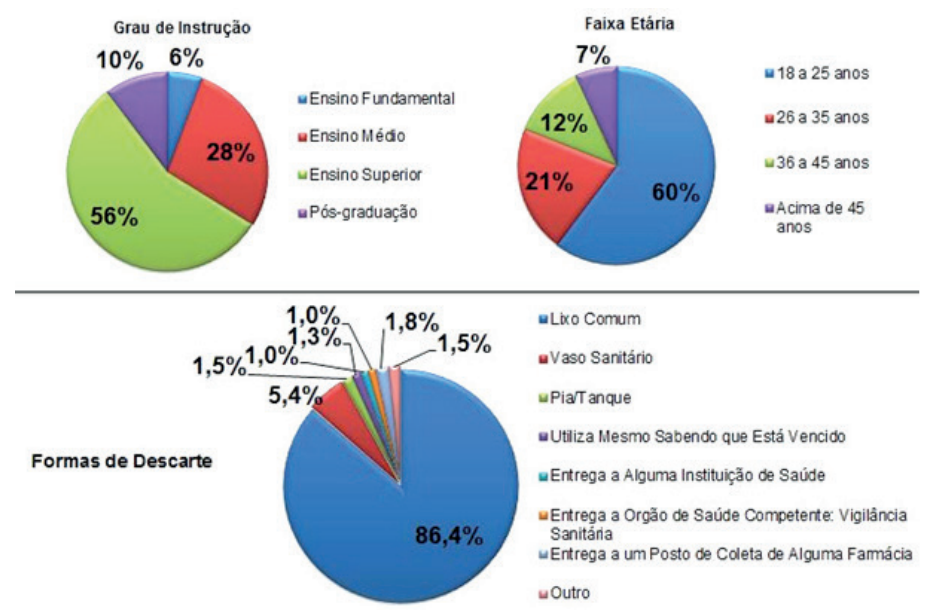

Gráfico 3 - Distribuição do grau de instrução, faixa etária dos pesquisados e as formas de descarte que praticam

Fonte: Elaborado pelas autoras com base na coleta de dados, 2015.

Quanto ao motivo para a forma de descarte de medicamentos utilizada, 53\% dos participantes afirmaram desconhecer os malefícios causados pelo descarte incorreto de medicamentos. O que reforça a hipótese de que a prática é comum devido o desconhecimento da população quanto ao impacto ambiental gerado. Quanto ao ponto coleta de resíduos medicamentosos, 96\% dos participantes afirmaram não conhecer nenhum ponto de coleta de medicamentos. O que reflete a necessidade de instalação de pontos de coleta, assim como a divulgação estruturada destes locais.
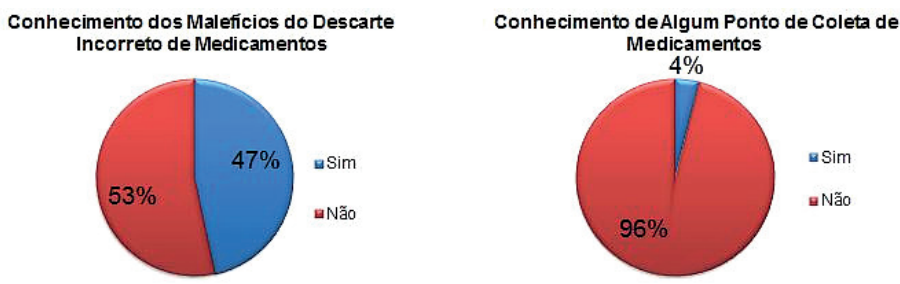

Gráfico 4 - Distribuição do percentual dos participantes que tem conhecimento dos malefícios do descarte incorreto de medicamentos, e do percentual que conhece algum ponto de coleta de medicamentos

Fonte: Elaborado pelas autoras com base na coleta de dados, 2015. 
Portanto, estes resultados reforçam as palavras de Ortiz, Boer e Rocha (2014) quando afirmam que o descarte inadequado é feito pela maioria das pessoas por falta de informação e divulgação sobre os danos causados pelos medicamentos ao meio ambiente e por carência de postos de coleta. Desta forma, "a criação de um público consciente é crucial para o sucesso de qualquer solução sustentável [...]” (Kongar et al., 2014, p. 55). Principalmente para a concepção, desenvolvimento e a consolidação de programas que solucionem o problema em questão.

\section{Considerações Finais}

Os resultados e discussões levantadas no presente estudo são extremamente relevantes, uma vez que são escassas as práticas de logística reversa de pós-consumo de medicamentos no país, bem como o assunto é pouco conhecido pelas pessoas comuns e pouco explorado pelos profissionais da área farmacêutica. Por outro lado, o assunto pode parecer algo muito específico, pequeno, simples, instrumental, mas que tem um potencial a ser explorado e alavancado. Sendo bem articulado pode promover simultaneamente a sustentabilidade ambiental, econômica e social.

Desta forma, faz-se necessário a criação de um sistema de gerenciamento adequado ao descarte de medicamentos gerados nas casas das pessoas, em conjunto com programas de sensibilização e educação que alertem as pessoas sobre o impacto ambiental gerado pelos resíduos medicamentosos no meio ambiente e sobre a forma correta de descarte dos medicamentos oriundos de sobras ou medicamentos vencidos.

O apoio dos órgãos e instituições competentes tende a ser fundamental para a criação de postos de coleta de medicamentos localizados nas drogarias e farmácias e, principalmente, no fomento ao incentivo a implantação de uma rede de logística reversa de pós-consumo de medicamentos envolvendo as indústrias, farmácias, drogarias e consumidores.

Ressalta-se, também, a importância de uma legislação que regulamente os processos de coleta e tratamento dos resíduos medicamentosos de forma a proteger o meio ambiente e a saúde pública. 


\section{Notas}

1 SINPRAFARMA: Sindicato dos Práticos de Farmácia e dos Empregados no Comércio de Drogas, Medicamentos e Produtos Farmacêuticos de São Paulo, fundado em 25 de julho de 1951.

\section{Referências}

ABCFARMA. Associação Brasileira do Comercio Farmacêutico. Faltam farmacêuticos em metade das farmácias do país, diz censo, 20 jan. 2014. Disponível em: < http://abcfarma.org.br/midia/faltam-farmaceuticos-em-metadedas-farmacias-do-pais-diz-censo.html>. Acesso em: 26 ago. 2015.

ABDI. Agência Brasileira de Desenvolvimento Industrial. Logística Reversa para o Setor de Medicamentos. 2013. Disponível em: <http://portal.anvisa.gov.br/wps/ wcm/connect/6035fe804362f6fbaca0be0eb77d2a7a/Log\%C3\%ADstica+Reversa +de+Medicamentos.pdf?MOD=AJPERES>. Acesso em: 27 ago. 2015.

ALVARENGA, L. S. V.; NICOLETTI, M. A. Descarte doméstico de medicamentos e algumas considerações sobre o impacto ambiental decorrente. Revista Saúde, UNG Online, v. 4, n. 3, p. 34-39, 2010. Disponível em: <http://revistas.ung.br/ index.php/saude/issue/view/34>. Acesso em: 05 nov. 2013.

BALLOU, R. H. Logística Empresarial. São Paulo: Atlas, 2010.

BHS. BRASIL HEALTH SERVICE. Programa Descarte Consciente. Disponível em: <http://www.bhsbrasil.com.br/descarteconsciente/instrucoes.htm>. Acesso em: 06 nov. 2015.

BRANDÃO, A. Logística reversa: Brasil busca solução para descarte inadequado de medicamentos. Revista Pharmacia Brasileira, Brasília, DF, v. 2, n. 87, p. 7-14, jan./mar. 2013.

BRASIL. Resolução da Diretoria Colegiada - RDC, n. 44, de 17 de agosto de 2009. Disponível em: <http://portal.anvisa.gov.br/wps/wcm/connect/4f6b6a80474575 cf83b9d73fbc4c6735/180809_rdc_44.pdf?MOD=AJPERES>. Acesso em: 15 ago. 2015.

BRASÍLIA. Política Nacional de Resíduos Sólidos (2012). 2. ed. Institui a Política Nacional de Resíduos Sólidos; altera a Lei no 9.605, de 12 de fevereiro de 1998; e dá outras providências. Brasília, DF: Câmara dos Deputados, 2012. Disponível em: <http://fld.com.br/catadores/pdf/politica_residuos_solidos.pdf >. Acesso em: 18 maio 2015.

CRF-GO. Conselho Regional de Farmácia Goiano. Disponível em: <http://www. crfgo.org.br/fale-com-o-crfgo/>. Acesso em: 05 nov. 2015.

DIAS, M. A. P. Logística, transporte e infraestrutura. São Paulo: Atlas, 2012.

GRACIANI, F. S.; FERREIRA, G. L. B. V. Descarte de Medicamentos: panorama da logística reversa no Brasil. Espacios, v. 35, n. 5, p. 11, 2014. Disponível em: 
<http://www.revistaespacios.com/a14v35n05/14350411.html>. Acesso em: 23 maio 2015.

IBGE. Instituto Brasileiro de Geografia e Estatística. Cidades. 2010. Disponível em: <http://cidades.ibge.gov.br/xtras/perfil.php?codmun=520870>. Acesso em: 27 ago. 2015

KONGAR, E. et al. A novel IT infrastructure for reverse logistics operations of end-of-life pharmaceutical products. Information Technology and Management, New York, v. 16, n. 1, p. 51-65, 2014. Disponível em: <http://link.springer.com/ article/10.1007\%2Fs10799-014-0195-z>. DOI: 10.1007/s10799-014-0195-z.>. Acesso em: 02 mar. 2016.

IMS Health. Disponível em: <http://www.imshealth.com/pt_BR>. Acesso em: 24 maio 2015.

JOÃO, W. da S. J. Descarte de medicamentos. Revista Pharmacia Brasileira, Brasília, DF, v. 82, n. 82, p. 14-16, jul./ago. 2011.

LEITE, M. Países assinam acordo inédito para conter aquecimento global. Folha de São Paulo, São Paulo, 12 dez. 2015. Disponível em: <http://www1.folha.uol. com.br/mundo/2015/12/1718310-franca-apresenta-proposta-para-cop21-selaracordo.shtml>. Acesso em: 15 dez. 2015.

LEITE, P. R. Logística Reversa: meio ambiente e competitividade. 2. ed. São Paulo: Pearson Prentice Hall, 2009.

LIVA, P. B. G.; OLIVEIRA, W. S.; PONTELO, V. S. L. Logística Reversa - I. 2002. Disponível em: <http://limpezapublica.com.br/textos/logistica_reversa_01. pdf $>$. Acesso em: 27 jul. 2015.

MUELLER, C. F. Logística Reversa: meio-ambiente e produtividade. GELOGUFSC, 2005. Disponível em: <http://web-resol.org/textos/artigo01_1.pdf>. Acesso em: 25 jul. 2015.

ORTIZ, J. da L. R.; BOER, N.; ROCHA, C. R. da. Descarte de medicamentos e logística reversa: entendimentos de uma comunidade escolar. In: SINTEC Seminário Internacional de Educação em Ciências, 2014, Rio Grande/RS. Anais... Rio Grande: FURG, 2014. p. 540-541. Disponível em: <http://webcache. googleusercontent.com/search?q=cache:T0mMo7TQdh8J: $w$ ww.santoangelo. uri.br/ciecitec/anaisciecitec/2015/resumos/poster/798.doc $+\& \mathrm{~cd}=1 \& \mathrm{hl}=$ pt$\mathrm{BR} \& \mathrm{ct}=\mathrm{clnk} \& \mathrm{gl}=\mathrm{br}>$. Acesso $\mathrm{em:} 07$ set. 2015

SILVA, T. H. H. da; SARQUIS, A. B.; TONDOLO, V. A. G. Marketing verde operações de agentes de logística de distribuição: estudo de caso em empresa de base tecnológica. Revista do ICSA: Gestão e Desenvolvimento, Novo Hamburgo: FEEVALE, v. 10, n. 1, p. 59-70, jan. 2013.

SINITOX. Sistema Nacional de Informações Tóxico-Farmacológicas. Descarte de Medicamentos domiciliares, 12 abr. 2016. Disponível em: $\leq$ http://sinitox.icict. fiocruz.br/descarte-de-medicamentos-domiciliares >. Acesso em: 12 abr. 2016

SINPRAFARMA. Sindicato dos Práticos de Farmácia e dos Empregados no Comércio de Drogas, Medicamentos e Produtos Farmacêuticos de São Paulo. Setor de Farmácias Cresce e Amplia Faturamento, 07 jul. 2014. Disponível em: 
<http://www.sinprafarmasp.org.br/noticia.php?nt=530>. Acesso em: 27 ago. 2015.

SPINA, G. A.; AQUINO, S. Contributions of Stakeholders of the Pharmaceutical Area in Sustainability Management of the Value Chain with the Implementation of Reverse Logistics Expired Products. CONTECSI, São Paulo, v. 12, abr. 2015. Disponível em: <http://www.contecsi.fea.usp.br/envio/index.php/ contecsi/12CONTECSI/paper/view/1890/2170 > . Acesso em: 05 set. 2015.

VAZ, T. As 10 maiores indústrias farmacêuticas do país em 2014. Exame, São Paulo, 22 jan. 2015. Disponível em: < http://exame.abril.com.br/negocios/noticias/ as-10-maiores-industrias-farmaceuticas-do-pais-em-2014/lista >. Acesso em: 10 set. 2015.

Alessandra Faria da Silva - Possui graduação em Administração pela Universidade Estadual de Goiás.

Vera Lúcia Francisco Dias Martins - Possui graduação em Administração pela Pontifícia Universidade Católica de Goiás e mestranda em Desenvolvimento e Planejamento Territorial pela Pontifícia Universidade Católica de Goiás. Atualmente é professora efetiva do Departamento de Administração da Universidade Estadual de Goiás.

Contribuição das autoras no desenvolvimento do trabalho

O trabalho teve suas etapas de concepção, delimitação da pesquisa, elaboração dos instrumentos de pesquisa, análise dos dados coletados, redação e revisão final elaborada pelas duas autoras. A aplicação e coleta de dados foi atividade designada à primeira autora; à segunda autora coube o desenvolvimento teórico conceitualà segunda autora coube o desenvolvimento teórico conceitual e a formatação do artigo.

Recebido para publicação em 11 de dezembro de 2016. Aceito para publicação em 19 de janeiro de 2017. 